\title{
Perencanaan Penjadwalan dengan Aplikasi BIM Menggunakan Analisa Probabilistik (Studi Kasus Proyek Jembatan Bedadung
}

\author{
Gabriel Henry, Supani dan Tri Joko Wahyu Adi \\ Departemen Teknik Sipil, Institut Teknologi Sepuluh Nopember (ITS) \\ e-mail: supani@ce.its.ac.id
}

\begin{abstract}
Abstrak-Perencanaan penjadwalan umunya dibuat secara manual sehingga hasil penjadwalan dapat terjadi perbedaan dengan desain. Untuk membuat jadwal yang terintergrasi dengan rancangan desain dapat menggunakan aplikasi BIM, namun penjadwalan BIM bersifat determistik. Untuk penjadwalan probabilistik dapat menggunakan metode PERT sebagain analisa probabilistiknya. Pada Tugas Akhir ini dilakukan modeling Proyek pembangunan Jembatan Bedadung pada aplikasi BIM berupa Tekla Structures dan dilakukan penjadwalan pada BIM menggunakan dua macam metode pelaksanaan, metode Service Crane dan metode Launcher Girder. Setelah dilakukan penjadwalan, maka dilakukan analisa probabilistik menggunakan Microsoft Project. Dari hasil analisa yang dilakukan didapatkan kesimpulan bahwa jadwal dengan metode Service Crane dan Launcher Girder perlu dilakukan iterasi penjadwalan dengan durasi 843 hari untuk metode service crane dan 853 hari untuk Launcher Girder agar memiliki tingkat keyakinan $75 \%$.
\end{abstract}

Kata Kunci-Penjadwalan, BIM, PERT, Microsoft Project.

\section{PENDAHULUAN}

$\mathrm{P}^{\mathrm{P}}$ ERANCANGAN konstruksi merupakan tahap mendesain sebuah bangunan, generasi terdahulu merancang secara manual menggunakan kertas dan sekarang dengan perkembangan teknologi, maka perancangan konstruksi dilakukan menggunakan CAD (Computer Aided Design). Dengan CAD desain yang dibuat adalah berupa gambar 2 dimensi atau 3 dimensi yang pada dasarnya sama dengan desain di kertas. Idealnya hasil desain mencakup informasi-informasi lainnya berupa laporan dan data, sehingga bila terjadi perubahan pada desain, maka laporan dan data yang ada akan berubah sesuai dengan desain yang baru.

Sebagai solusinya, maka dapat menggunakan BIM (Building Information Modeling). Model digital dari BIM memiliki wujud, geometrik, dan informasi yang menggambarkan desain bangunan sesungguhnya. Model ini berupa objek digital, bukan hanya sekedar kumpulan garis geometrik. Satu model dalam BIM merupakan sebuah database yang dapat mengeluarakan seluruh informasi yang dibutuhkan dalam merencanakan suatu konstruksi, mulai dari tampak, denah, detail, scheduling, dan informasi lainnya. Karena model BIM merupakan suatu kesatuan, maka perubahan pada salah satu data akan langsung teraplikasikan ke seluruh model, sehingga bila terjadi perubahan dalam desain, maka laporan dan data yang ada akan ikut berubah sesuai dengan desain yang baru. Dengan BIM laporanlaporan dapat dibuat secara otomatis dan terintegrasi, seperti dalam pembuatan schedule konstruksi. Dalam penyusunan schedule menggunakan BIM dapat terlihat dengan jelas objek mana yang dikerjakan sehingga bila terjadi perubahan desain seperti perubahan jumlah objek atau volume objek, maka dengan otomatis schedule akan menyesuaikan dengan volume desain yang baru.

Hasil dan informasi yang didapat dari BIM bersifat deterministik yang mana seluruh variabel bersifat pasti, sesuai dengan data yang dimasukkan. Dalam scheduling menggunakan BIM, durasi pengerjaan tiap objek akan mengikuti data yang ditentukan sebelumnya. Nyatanya dalam praktik konsruksi ada variabel-variabel yang bersifat tidak pasti atau probabilistik. Oleh karena itu dalam perancangan metode konstruksi dan scheduling, data yang didapat dari BIM perlu diintegrasikan dengan model pobabilistik agar dapat menggambarkan kondisi sesungguhnya dengan menggunakan analisis probabilistik.

Analisis probabilistik dapat dilakukan dengan menggunakan program bantu Microsoft Project. Dari penjadwalan yang dilakukan pada BIM akan diolah pada Microsoft Project menggunakan metode PERT (Programme Evaluation and Review Technique) untuk mengetahui berapa besar kemungkinan jadwal yang dibuat untuk selesai tepat waktu. Karena itu penelitian ini menerapkan model probalistik terhadap model BIM agar dapat menggambarkan dan memprediksi pekerjaan konstruksi yang akan dilaksanakan secara real atau sesuai dengan aslinya, sehingga perencana dapat mengetahui berapa besar kredibilitas suatu jadwal.

\section{TINJAUAN PUSTAKA}

Proyek adalah suatu usaha untuk mencapai tujuan tertentu dengan batasan waktu dan sumber daya. Pengertian proyek konstruksi sendiri adalah suatu usaha untuk mencapai suatu hasil berupa bangunan atau infrastruktur. Dalam praktiknya proyek konstruksi umumnya mencakup pekerjaan teknik sipil dan arsitektural, selain itu juga dapat melibatkan pekerjaan lain seperti teknik industri, teknik mesin, teknik elektro, dan sebagainya.

Manajemen proyek konstruksi adalah penerapan dari perencanaan, pelaksanaan, dan penerapan secara sistematis pada sebuah proyek konstruksi dengan menggunakan waktu dan sumber daya secara efektif dan efisien agar tujuan proyek tercapai dengan optimal. Manajemen konstruksi meliputi mutu fisik, biaya, dan waktu konstruksi. Manajemen perencanaan meliputi manajemen material dan manajemen 


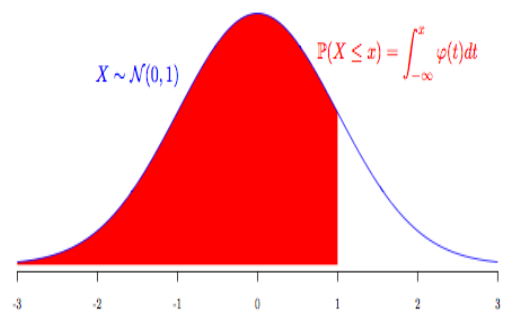

Gambar 1. Distribusi Normal

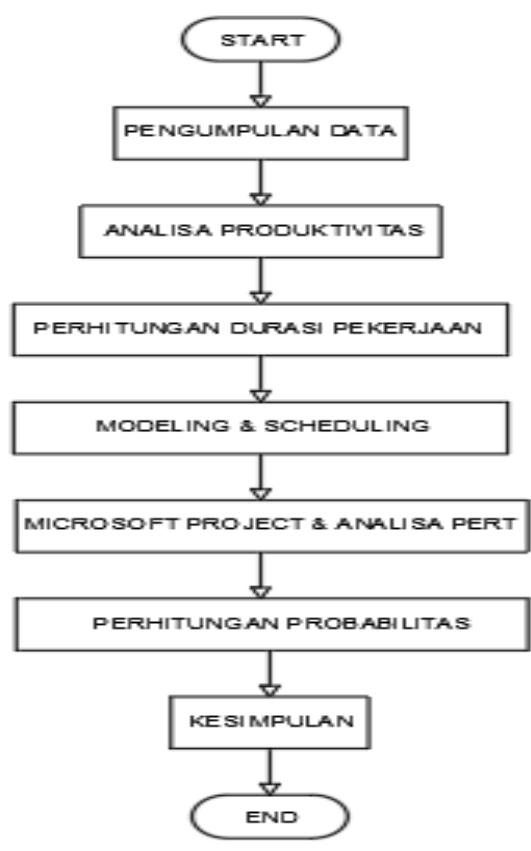

Gambar 2. Diagram alir penyelesaian Tugas Akhir

tenaga kerja Manajemen pelaksanaan meliputi pengendalian waktu dan biaya proyek. Manajemen waktu pada suatu proyek memasukkan semua proses yang dibutuhkan dalam upaya untuk memastikan waktu penyelesaian proyek [1].

PERT merupakan teknik analisa penjadwalan yang dibuat untuk menganalisa probabilitas yang terjadi pada penjadwalan. PERT pertama kali dikembangkan pada tahun 1956-58 untuk membantu prencanaan dan penjadwalan misil kapal selam nuklir milik angkatan laut Amerika Serikat yang mana mencakup ribuan pekerjaan. Teknik ini terbukti berguna untuk semua pekerjaan yang memiliki durasi tidak pasti seperti dalam proyek baru [2]. Dengan menggunakan teknik PERT untuk melakukan analisa penjadwalan, maka dapat diperkirakan berapa persen kemungkinan suatu kegiatan dapat selesai tepat waktu. Selain itu, dengan teknik ini perencana juga dapat mengetahui berapa persen kemungkinan suatu pekerjaan terjadi keterlambatan. PERT digunakan karena perhitungan yang diperlukan tidak rumit dan mudah dimengerti.

Data yang diperlukan untuk melakukan analisa PERT adalah durasi paling optimis, durasi yang paling sering terjadi, dan durasi paling pesimis. Langkah-langkah perhitungan PERT adalah sebagai berikut; (1)Menghitung rata-rata durasi pekerjaan, dengan durasi yang paling sering terjadi memiliki bobot empat kali dari durasi paling optimis dan durasi paling pesimis.
Tabel 1

WBS Metode Launcher Girder

\begin{tabular}{ll}
\hline \hline Pekerjaan & Sub-pekerjaan \\
\hline 1.Abutment & 1.1 Pembuatan Bekisting Pile cap \\
& 1.2 Penulangan Pile Cap \\
& 1.3 Pengecoran Pile Cap \\
& 1.4 Pembuatan Bekisting Abutment \\
& 1.5 Penulangan pile Abutment \\
& 1.6 Pengecoran Abutment \\
& 2.1 Pembuatan Bekisting Pile cap \\
2.2 Penulangan Pile Cap & 2.3 Pengecoran Pile Cap \\
2.Pilar & 2.5 Pembuatan Bekisting Pilar \\
& 2.6 Pengecoran Pilar \\
& 3.1 Pengangkutan \\
& 3.2 Pemasangan Tulangan \\
& 3.3 PreStressing \\
3.4 Instalasi Launcher Girder & 3.5 Pemasangan Elastomer \\
3.Balok Girder & 3.6 Pemasangan Girder \\
& 3.7 Instalasi Gider \\
4.1 Pembuatan Bekisting Plat Lantai & 4.2 Penulangan Plat Lantai \\
& 4.3 Pengecoran Plat Lantai \\
\hline \hline
\end{tabular}

Tabel 2.

WBS Metode Service Crane

\begin{tabular}{|c|c|}
\hline Pekerjaan & Sub-pekerjaan \\
\hline \multirow[t]{6}{*}{ 1.Abutment } & 1.1 Pembuatan Bekisting Pile cap \\
\hline & 1.2 Penulangan Pile Cap \\
\hline & 1.3 Pengecoran Pile Cap \\
\hline & 1.4 Pembuatan Bekisting Abutment \\
\hline & 1.5 Penulangan pile Abutment \\
\hline & 1.6 Pengecoran Abutment \\
\hline \multirow[t]{6}{*}{ 2.Pilar } & 2.1 Pembuatan Bekisting Pile cap \\
\hline & 2.2 Penulangan Pile Cap \\
\hline & 2.3 Pengecoran Pile Cap \\
\hline & 2.4 Pembuatan Bekisting Pilar \\
\hline & 2.5 Penulangan Pilar \\
\hline & 2.6 Pengecoran Pilar \\
\hline \multirow[t]{8}{*}{ 3.Balok Girder } & 3.1 Pengangkutan \\
\hline & 3.2 Pemasangan Tulangan \\
\hline & 3.3 PreStressing \\
\hline & 3.4 Pemasangan Service Crane \\
\hline & $\begin{array}{l}\text { 3.5 Penggangkutan Service Crane ke } \\
\text { kapal }\end{array}$ \\
\hline & 3.6 Pemasangan Elastomer \\
\hline & 3.7 Pemasangan Girder \\
\hline & 3.8 Instalasi Gider \\
\hline \multicolumn{2}{|l|}{ 4.Plat Lantai } \\
\hline Jembatan & 4.1 Pembuatan Bekisting Plat Lantai \\
\hline & $\begin{array}{l}\text { 4.2 Penulangan Plat Lantai } \\
\text { 4.3 Pengecoran Plat Lantai }\end{array}$ \\
\hline
\end{tabular}

Mean $=($ Durasi optimis +4 Durasi paling sering + Durasi pesimis $) / 6$

(2) Menghitung Variance dan Standar Deviasi.

Variance $=($ Durasi Pesimis - Durasi Optimis $) / 6$

$$
\text { Standar Deviasi }=(\sqrt{\text { Variance }})
$$

(3)Untuk menghitung berapa persen kemungkinan kegiatan selesai sebelum $\mathrm{X}$ hari, maka, dicari distribusi normalnya.

$$
Z(\text { Distribusi normal })=\frac{X-\text { Mean }}{\sqrt{\text { Variance }}}
$$

(4)Dari distribusi normal mencari persen luas diagram normal untuk mendapatkan kemungkinan kegiatan selesai sebelum X hari distribusi normal seperti pada Gambar 1. 
Tabel 3.

Produktivitas

\begin{tabular}{|c|c|c|c|c|c|}
\hline \multirow{2}{*}{ Pekerjaan } & \multirow{2}{*}{ Sub-pekerjaan } & \multicolumn{3}{|c|}{$\begin{array}{l}\text { Produktivitas } \\
\end{array}$} & \multirow{2}{*}{ Volume } \\
\hline & & Pesimis & Paling mungkin & Optimis & \\
\hline \multirow[t]{6}{*}{ 1.Abutment } & 1.1 Pembuatan Bekisting Pile cap & 9.38 & 12.50 & 18.75 & $\mathrm{~m}^{2} / \mathrm{jam}$ \\
\hline & 1.2 Penulangan Pile Cap & 41.67 & 53.57 & 187.50 & $\mathrm{~kg} / \mathrm{jam}$ \\
\hline & 1.3 Pengecoran Pile Cap & 29.38 & 58.75 & 58.75 & $\mathrm{~m}^{3} / \mathrm{jam}$ \\
\hline & 1.4 Pembuatan Bekisting Abutment & 3.13 & 6.25 & 12.50 & $\mathrm{~m}^{2} / \mathrm{jam}$ \\
\hline & 1.5 Penulangan Abutment & 87.50 & 175.00 & 175.00 & $\mathrm{~kg} / \mathrm{jam}$ \\
\hline & 1.6 Pengecoran Abutment & 0.53 & 1.05 & 1.75 & $\mathrm{~m}^{3} / \mathrm{jam}$ \\
\hline \multirow[t]{6}{*}{ 2.Pilar } & 2.1 Pembuatan Bekisting Pile cap & 9.38 & 12.50 & 18.75 & $\mathrm{~m}^{2} / \mathrm{jam}$ \\
\hline & 2.2 Penulangan Pile Cap & 41.67 & 53.57 & 187.50 & $\mathrm{~kg} / \mathrm{jam}$ \\
\hline & 2.3 Pengecoran Pile Cap & 29.38 & 58.75 & 58.75 & $\mathrm{~m}^{3} / \mathrm{jam}$ \\
\hline & 2.4 Pembuatan Bekisting Pilar & 3.13 & 6.25 & 12.50 & $\mathrm{~m}^{2} / \mathrm{jam}$ \\
\hline & 2.5 Penulangan Pilar & 87.50 & 175.00 & 175.00 & $\mathrm{~kg} / \mathrm{jam}$ \\
\hline & 2.6 Pengecoran Pilar & 2.50 & 5.00 & 8.33 & M3/jam \\
\hline \multirow[t]{12}{*}{ 3.Balok Girder } & 3.1 Pengangkutan & 3.00 & 3.20 & 6.00 & unit/jam \\
\hline & 3.2 Pemasangan Tulangan & 1.33 & 4.00 & 4.00 & unit/jam \\
\hline & 3.3 PreStressing & 0.13 & 0.50 & 1.00 & unit/jam \\
\hline & 3.4 Instalasi Launcher Girder & 0.02 & 0.03 & 0.03 & unit/jam \\
\hline & 3.5 Pemasangan Service Crane & 0.05 & 0.06 & 0.06 & unit/jam \\
\hline & 3.6 Penggangkutan Service Crane ke & & & & \\
\hline & $\begin{array}{l}\text { kapal } \\
\text { 37 Pemasangan Elastomer }\end{array}$ & $\begin{array}{l}0.05 \\
0.63\end{array}$ & $\begin{array}{l}0.07 \\
1.00\end{array}$ & $\begin{array}{l}0.07 \\
6.00\end{array}$ & $\begin{array}{l}\text { unit/jam } \\
\text { unit/jam }\end{array}$ \\
\hline & 3.8 Pemasangan Girder dengan & & & & \\
\hline & launcher & 0.25 & 0.40 & 0.50 & unit/jam \\
\hline & 3.9 Pemasangan Girder dengan & & & & \\
\hline & crane & 0.22 & 0.67 & 2.00 & unit/jam \\
\hline & 3.10 Instalasi Gider & 0.17 & 0.25 & 0.25 & unit/jam \\
\hline \multirow[t]{3}{*}{ 4.Plat Lantai Jembatan } & 4.1 Pembuatan Bekisting Plat Lantai & 0.49 & 0.63 & 1.09 & $\mathrm{~m}^{2} / \mathrm{jam}$ \\
\hline & 4.2 Penulangan Plat Lantai & 2.67 & 4.00 & 8.00 & $\mathrm{~kg} / \mathrm{jam}$ \\
\hline & 4.3 Pengecoran Plat Lantai & 8.50 & 10.63 & 14.17 & $\mathrm{~m}^{3} / \mathrm{jam}$ \\
\hline
\end{tabular}

Tabel 4.

Proses input

\begin{tabular}{lllll}
\hline \hline \multirow{2}{*}{ Pekerjaan } & Objek & Proses Input & & \\
& Pilecap & Otomatis & Semi-Otomatis & Manual \\
\hline \multirow{3}{*}{ Abutmen } & Pilar Abutmen & Tidak & Ya & Ya \\
& Penulangan pilecap & Tidak & Tidak & Ya \\
& Penulangan Abutmen & Tidak & Tidak & Ya \\
\multirow{4}{*}{ Pilar } & Pilecap & Tidak & Tidak & Ya \\
& Pilar & Tidak & Ya & Ya \\
\multirow{2}{*}{ Bolak Girder } & Penulangan pilecap & Tidak & Tidak & Ya \\
\multirow{2}{*}{ Plat Lantai } & Penulangan Pilar & Tidak & Tidak & Ya \\
& Balok & Tidak & Ya & Ya \\
\hline \hline
\end{tabular}

\section{PETUNJUK TAMBAHAN}

Urutan pekerjaan penyelesaian Tugas Akhir dilakukan dengan tahapan- tahapan dapat dilihat pada Gambar 2. Pengumpulan data untuk perencanaan gedung meliputi gambar struktur, gambar arsitek dan data tanah.

$$
\begin{aligned}
& \text { - Nama Proyek : Jembatan Bedadung } \\
& \text { - Lokasi : Kali Bedadung, Puger, Jawa } \\
& \text { Timur } \\
& \text { - Konsultan : PT. Aria Jasa Reksatama } \\
& \text { - Jenis Pekerjaan : Pembangunan Jembatan } \\
& \text { - Jenis Konstruksi : Jembatan } \\
& \text { - Bentang Jembatan: } 292 \text { meter }
\end{aligned}
$$

\section{DATA DAN PENGOLAHAN DATA}

\section{A. Metodologi Pengerjaan Jembatan}

Pengerjaan dibagi menjadi 4 jenis pekerjaan, pekerjaan Abutment, pekerjaan Pilar, pekerjaan balok girder, dan pekrejaan Plat Lantai, Pekerjaan Abutment dibagi menjadi tiga tahap, pembuatan bekisting, pembuatan dan pemasangan tulangan, dan pengecoran Pekerjaan Pilar Jembatan dibagi menjadi lima tahap, pemasangan Sheet Piles, pemompaan air, pembuatan bekisting, penulangan, dan pengecoran.

Pekerjaan pemasangan Balok Girder, pekerjaan dibagi menjadi empat tahap, pengangkutan girder ke lokasi, Prestressing, Placing girder ke pilar jembatan, dan instalasi girder. Placing girder sendiri ada dua alternatif metode yaitu, menggunakan launcher dan menggunakan service crane. Metode launcher ada 2 tahapan, yaitu setting dan pemasangan alat dan penempatan girder menggunakan launcher. Metode service crane memiliki tiga tahapan, yaitu pengangkutan crane ke atas kapal, setting crane, dan pemasangan girder menggunakan crane. Pekerjaan Plat Lantai Jembatan ini terdiri dari tiga tahapan, pembuatan bekisting, pembuatan dan pemasangan tulangan, dan pengecoran. Pekerjaan di atas dengan launcher girder dibagi menjadi sub-pekerjaan seperti pada Tabel 1 dan dengan service crane dibagi menjadi seperti Tabel 2.

\section{B. Metodologi Pengerjaan Jembatan}

Produktivitas didapat dari Expert Judgement, sebagai 
expert adalah Bapak Hartono Suko selaku ahli struktur di PT. Virama Karya. Produktivitas yang dibutuhkan adalah produktivitas yang paling mungkin terjadi, produktivitas dalam kondisi paling pesimis dan produktivitas pada kondisi paling optimis. Data yang didapat sepeti pada Tabel 3. Produktivitas pada kondisi pesimis merupakan produktivitas dengan asumsi bahwa sering terjadi hujan, keterlambatan pada bahan yang akan digunakan, dan kerusakan terhadap peralatan yang digunakan. Sedangkan kondisi paling mungkin adalah kondisi dengan jumlah kendala sedikit dan kondisi optimis adalah kondisi tanpa kendala dan bahan sudah tersedia.

\section{PEMODELAN DAN PENJADWALAN}

\section{A. Metodologi Pengerjaan Jembatan}

Modeling struktur pada BIM merupakan proses menuangkan gambar informasi dan desain ke dalam aplikasi BIM, dalam Tugas Akhir ini merupakan data dan gambar dari CAD ke media BIM berupa aplikasi Tekla Structures. Proses input ke dalam BIM dapat digolongkan menjadi tiga macam yaitu, Otomatis, Semi-otomatis dan Manual. Proses input objek yang dikerjakan pada Tugas Akhir ini adalah seperti pada Tabel 4. Dalam penjadwalan BIM ada beberapa komponen yang diperlukan, yaitu Pekerjaan, Volume Pekerjaan, Durasi Pekerjaan, Urutan Pengerjaan atau pendahulu, dan jadwal itu sendiri. Komponen tersebut juga dapat digolongkan menjadi Otomatis, Semi-Otomatis dan Manual. Pekerjaan dibuat secara manual dengan melakukan input jenis pekerjaan dan objek yang dikerjakan sedangkan Volume pekerjaan akan Otomatis ada saat pekerjaan dibuat dan diberi objek.

Model jadwal probabilistik dibuat dengan bantuan Microsoft Project. Data penjadwalan yang ada pada BIM diimpor ke dalam Microsoft Project dan dilakukan analisa menggunakan Metode PERT. Dalam proses menghubungkan BIM dengan Microsoft Project terdapat ketidak selarasan sehingga durasi pekerjaan yang muncul pada Microsoft Project tidak sesuai dengan durasi yang mucul pada BIM. Oleh karena itu durasi pesimis, paling mungkin dan optimis yang akan digunakan pada analisa PERT dimasukkan secara manual ke Microsoft Project. Perhitungan estimasi durasi PERT dan variance dapat dilakukan secara semi-otomatis dengan memasukkan formula yang digunakan pada Microsoft Project.

\section{B. Hasil}

Hasil dapat dilakukan dengan 2 metode antara lain: (1)Metode service crane. Durasi total pada jalur kritis untuk metode service crane dari penjadwalan pada BIM adalah 743.01 hari. Durasi total dari estimasi PERT yang dilakukan pada Microsoft project adalah 834.5 hari dengan variance 154.58

$$
\begin{gathered}
\text { Distribusi Normal }=\frac{743.01-834.5}{\sqrt{154.58}} \\
\text { Distribusi Normal }=-7.36
\end{gathered}
$$

Maka mengacu pada Tabel Distribusi Normal, kemungkinan proyek Jembatan Bedadung akan selesai sesuai atau lebih cepat dari yang dijadwalkan menggunakan Metode Service Crane adalah mendekati $0 \%$. Bila proyek diharap selesai dengan tingkat keyakinan 75\%, maka durasi yang dibutuhkan adalah 843 hari; (2)Metode Launcher Girder. Durasi total pada jalur kritis untuk metode launcher girder dari penjadwalan pada BIM adalah 847.28 hari. Durasi total dari estimasi PERT yang dilakukan pada Microsoft project adalah 834.5 hari dengan variance 152.56

$$
\begin{gathered}
\text { Distribusi Normal }=\frac{847.25-844.92}{\sqrt{152.56}} \\
\text { Distribusi Normal }=0.19107
\end{gathered}
$$

Maka mengacu pada Tabel Distribusi Normal, kemungkinan proyek Jembatan Bedadung akan selesai sesuai atau lebih cepat dari yang dijadwalkan menggunakan Metode Service Crane adalah $57.5 \%$. Bila proyek diharap selesai dengan tingkat keyakinan $75 \%$, maka durasi yang dibutuhkan adalah 853 hari.

\section{Analisa}

Dari Analisa PERT dapat disimpulkan jadwal yang dibuat dengan metode Launcher Girder lebih dapat diandalkan dari pada metode Service Crane, karenajadwal dengan Metode Launcher Girder memiliki tingkat keyakinan $57.5 \%$ dan Metode Service crane mendekati $0 \%$. Untuk itu bila jadwal diharapkan memiliki tingkat keyakinan paling tidak $75 \%$, maka pelu dilakukan iterasi penjadwalan dengan durasi 843 hari untuk Metode Service Crane dan durasi 853 hari untuk Metode Launcher Girder. Tingkat keyakinan yang didapat tidaklah absolut karena analisa PERT merupakan pendekatan. Analisa PERT menggunakan distribusi beta sedangkan peristiwa nyata distribusi durasi belum tentu merupakan distribusi beta.

\section{KESIMPULAN DAN SARAN}

\section{A. Pemodelan Konstruksi dan Penjadwalan pada BIM}

Membuat model struktur dengan menggunakan BIM tidak dapat dilakukan secara Otomatis tetapi dalam beberapa bagian yang sering digunakan dalam konstuksi dapat dibuat secara Semi-Otomatis sehingga mempermudah dalam pembuatan model struktur. Sebagian objek konstruksi meski tidak dapat dibuat secara otomatis masih bisa dibuat secara manual menggunakan alat yang tersedia pada BIM. Penjadwalan pada BIM pada dasarnya sama dengan penjadwalan dengan media bantu lainnya, tapi keunggulan dari BIM adalah volume pekerjaan sudah didapat secara Otomatis sehingga mempermudah penjadwalan, selain itu durasi pekerjaan juga dapat dihitung dengan Semi-Otomatis dengan BIM sehingga mempermudah penjadwalan. Melakukan pemodelan struktur dan penjadwalan dengan BIM dapat mempermudah dalam pembuatan jadwal terutama bila proyek yang dikerjakan memiliki berbagai macam komponen yang memiliki kesamaan satu dengan yang lain.

\section{B. 6.2 Analisa PERT Menggunakan Microsoft Project}

Dengan menggunakan Microsoft Project, maka data yang masuk merupakan data yang di-export dari BIM namun data yang masuk ke dalam Microsoft Project tidak sesuai dengan data yang ada pada BIM karena perubahan format sehingga data durasi yang akan digunakan dalam Analisa PERT perlu dimasukkan secara manual. Jalur kritis dapat dicari otomatis dengan Microsoft Project sehingga tidak perlu dicari secara 
manual. Dari proses pemasukkan data pada Microsoft Project akan menghasilkan durasi PERT dan variance yang akan digunakan untuk mendapatkan distribusi normal pada penjadwalan. Hasil akhir analisa PERT perlu dicari dan dihitung secara manual sehingga mendapatkan tingkat keyakinan jadwal akan selesai tepat waktu. Meski demikian proses ini sangat penting untuk mendapat jadwal iterasi ke-2.

\section{Kemungkinan Pekerjaan Selesai Tepat Waktu}

Dengan menggunakan metode Service Crane kemungkinan pekerjaan selesai tepat waktu atau lebih cepat dari perkiraan adalah mendekati nol bila menggunakan jadwal semula yang direncanakan pada BIM dan kemungkinan Pekerjaan menggunakan metode Launcher Girder selesai tepat waktu atau lebih cepat adalah $57.5 \%$ bila menggunakan jadwal semula. Bila diberi kriteria bahwa jadwal harus memiliki tingkat keyakinan minimal 75\%, maka metode Service Crane perlu dijadwalkan dengan durasi 843 hari dan metode Launcher Girder 853 hari. Pada penjabaran di atas dapat disimpulkan bahwa target penyelesaian proyek Jembatan Bedadung yang paling cepat adalah 843 hari dengan Metode Srevice Crane.

\section{Saran}

Bila dilakukan penelitihan lebih lanjut atau serupa dapat dilakukan validasi dari hasil penjadwalan yang dilakukan untuk mengetahui kebenaran dari jadwal yang dihasilkan.

\section{DAFTAR PUSTAKA}

[1] P. M. Institute, "A Guide to Project Management Body of Knowlage," Pennsylvania Newt. Sq., 2000.

[2] S. C. Sharma, Operation Research: Pert, Cpm \& Cost Analysis. New Delhi: Discovery Publishing House, 2006. 